\title{
Review: maximum androgen blockade does not confer additional survival benefit to androgen suppression in prostate cancer
}

Prostate Cancer Trialists' Collaborative Group. Maximum androgen blockade in advanced prostate cancer: an overview of the randomised trials. Lancet 2000 Apr 29;355:1491-8.

QUESTION: In men with prostate cancer, is maximum androgen blockade (MAB) better than androgen suppression (AS) alone for prolonging survival?

\section{Data sources}

Studies were identified by searching computerised databases, trial registers, meeting abstracts, and reference lists and by contacting investigators and pharmaceutical companies.

\section{Study selection}

Studies were selected if they were randomised trials that began before 1991 and compared MAB (AS plus an antiandrogen, such as nilutamide, flutamide, or cyproterone acetate) with AS alone and if the treatment was given for $\geqslant 1$ year.

\section{Data extraction}

Information was requested for each patient on stage of disease, age at randomisation, date of randomisation, treatment allocation, date of last follow up, date of death, and cause of death.

\section{Main results}

1 trials met inclusion criteria; individual patient data were obtained for 27 trials ( 8275 men). Analysis was by intention to treat. 12 trials evaluated flutamide (4803 men), 8 trials evaluated nilutamide (1688 men), and 7 trials evaluated cyproterone acetate (1784 men). The total mortality rate was $70.4 \%$ in patients receiving $\mathrm{MAB}$ and $72.4 \%$ in patients receiving AS alone $(\mathrm{p}=0.11)$. The table shows the 5 year overall survival rates. No significant heterogeneity existed among the studies according to patient age group or disease stage. A survival benefit was shown in studies for which nilutamide or flutamide was used as the antiandrogen $(\mathrm{p}=0.005)$, and a decrease in survival occurred in trials that used cyproterone acetate $(\mathrm{p}=0.04)$ (table).

Maximum androgen blockade (MAB) $v$ androgen suppression (AS) alone for overall survival at 5 years in advanced prostate cancer (individual patient data from 27 trials)*

\begin{tabular}{|c|c|c|c|c|}
\hline MAB (all 3 drugs) & AS & $\begin{array}{l}\mathrm{ABI} \\
(95 \% \mathrm{CI})\end{array}$ & $\mathrm{RBI}$ & NNT (Cl) \\
\hline $25.4 \%$ & $23.6 \%$ & $\begin{array}{l}1.8 \% \\
(-0.7 \text { to } 4.3)\end{array}$ & $7.6 \%$ & $\begin{array}{l}\text { Not } \\
\text { significant }\end{array}$ \\
\hline \multicolumn{5}{|c|}{ MAB (nilutamide or flutamide) } \\
\hline $27.6 \%$ & $24.7 \%$ & $\begin{array}{l}2.9 \% \\
(0.4 \text { to } 5.4)\end{array}$ & $11.7 \%$ & $\begin{array}{l}35 \\
\text { (19 to } 250)\end{array}$ \\
\hline MAB (cyproterone & cetate) & $\mathrm{ABR}(\mathrm{Cl})$ & RBR & NNH \\
\hline $15.4 \%$ & $18.1 \%$ & $\begin{array}{l}2.8 \% \\
(-1.9 \text { to } 7.5)\end{array}$ & $15 \%$ & $\begin{array}{l}\text { Not } \\
\text { significant }\end{array}$ \\
\hline
\end{tabular}

${ }^{*} \mathrm{ABR}=$ absolute benefit reduction; $\mathrm{RBR}=$ relative benefit reduction. Othe abbreviations defined in glossary; RBI, RBR, NNT, NNH, and Cl calculated from data in article.

\section{Conclusion}

In men with advanced prostate cancer, the addition of an antiandrogen to androgen suppression alone does not confer a statistically significant survival benefit at 5 years.

\section{COMMENTARY}

The Prostate Cancer Trialists' Collaborative Group (PCTCG) study shows that adding a non-steroidal antiandrogen (NSAA) to androgen suppression produces a statistically significant increase in long term survival over AS alone. The real question is whether the difference of $2.9 \%$ (CI $0.4 \%$ to $5.4 \%$ ) is clinically significant. The answer is, "probably not."

The issue hinges on symptoms and quality of life. Adding an NSAA to medical or surgical castration, thereby achieving $\mathrm{MAB}$, increases the likelihood of side effects from treatment. Men who have been castrated experience menopausal type symptoms. NSAA drugs add the risk for further, predominantly gastrointestinal, toxicity. A recent, literature based meta-analysis showed that about $10 \%$ of patients receiving $\mathrm{MAB}$ stop treatment because of side effects; the percentage for patients receiving AS alone is 4\%. ${ }^{1}$ The evidence on overall quality of life is both limited and conflicting. ${ }^{23}$ Given such evidence, it is difficult to justify the additional expense of the NSAA: a year's supply of flutamide at a dose of $750 \mathrm{mg}$ per day costs $£ 1100$.

MAB was introduced with high hopes, but the measurable benefits are far less than originally predicted Pathophysiological theories may inform clinical practice, but they cannot, in the presence of clear evidence to the contrary, dictate it.

Adding an NSAA to castration may slightly improve the chances of a man with metastatic prostate cancer surviving a further 5 years. However, the risks for increased toxicity and, possibly, impaired quality of life have to be set against this minor benefit.

Alastair J Munro, MRCP, BSc Ninewells Hospital and Medical School Dundee, $U K$

1 Schmitt B, Bennett C, Seidenfeld J, et al. Maximal androgen blockade for advanced prostate cancer. Cochrane Database Syst Rev 2000;(2):CD001526.

2 Rosendahl I, Kiebert GM, Curran D, et al. Quality adjusted survival (Q-TwiST) analysis of EORTC trial 30853: comparing goserelin acetate and flutamide with bilateral orchiectomy in patients with metastatic prostate cancer. European organization for research and treatment of cancer. Prostate 1999;1:100-9.

3 Moinpour CM, Savage MJ, Troxel A, et al. Quality of life in advanced prostate cancer: results of a randomized therapeutic trial.J Natl Cancer Inst 1998;90:1537-44.
Sources of funding: Netherlands Cancer Institute; Imperial Cancer Research Fund; UK Medical Research Council; European Union.

For correspondence: PCTCG Secretariat, Biometrics Department, Netherlands Cancer Institute, Plesmanlaan 121, $1066 \mathrm{Cx}$ Amsterdam, the Netherlands. Fax +31 206172625. 